\title{
DESTINAÇÃO DE CARCAÇAS DE ANIMAIS MORTOS PROVENIENTES DE SUINOCULTURA EM GRANJA NO ESTADO DO PARANÁ
}

\section{ANIMAL CARCASS OF DESTINATION DEAD FROM PIG INDUSTRY IN THE STATE OF PARANÁ}

\author{
Rafaela Franqueto ${ }^{1}$ \\ Angelo Antonio Delponte ${ }^{2}$ \\ Renan Franqueto ${ }^{3}$ \\ Jonas Andre Bankersen ${ }^{4}$
}

\section{Resumo}

A suinocultura no Brasil e no Paraná, tem sido uma atividade tradicional, implementada em pequenas propriedades rurais. A suinocultura brasileira está bem consolidada, e podemos identificar isso devido ao país ser o $4^{\circ}$ maior produtor e exportador de carne suína no âmbito mundial. O rebanho é estimado em 2,4 milhões de matrizes, e com uma cadeia produtiva reunindo em torno de 50 mil produtores. Tem - se observado expansão na atividade, e assim, consequentemente, deve - se ter cada vez mais interesse na destinação correta dos dejetos e resíduos produzidos pelo rebanho que possuímos em todo o nosso país $\mathrm{O}$ objetivo deste trabalho foi caracterizar o sistema de criação de suínos e as destinações dos resíduos gerados por estas criações. Para coleta dos dados, foram realizadas visitas "in loco" e coletados os dados: sistema de produção, número de animais, taxa de mortalidade, destinação da carcaça dos animais mortos e destinação dos dejetos. A partir do levantamento verificou-se que o sistema de destinação e tratamento da carcaça dos animais era realizado por compostagem. A granja encontra-se em conformidade com a legislação ambiental nacional e estadual.

Palavras-chave: suinocultura; compostagem; carcaças de suínos; dejetos da suinocultura

\begin{abstract}
The pig industry in Brazil and Paraná, has been a traditional activity, implemented in small farms. Brazilian pig farming is well established, and we can identify it because of the country is the 4th largest producer and exporter of pork worldwide. The herd is estimated at 2.4 million sows, and a supply chain bringing together around 50 thousand producers. It has - been observed expansion in activity, and so therefore should - have increasingly interested in the proper disposal of waste and waste produced by the herd we have throughout our country The aim of this study was to characterize the system of rearing pigs and the destinations of the waste generated by these creations. For data collection, visits were made "in situ" and collected the data: production system, number of animals, mortality rate, carcass disposal of dead animals and disposal of waste. From the survey it was found that the system of allocation and treatment of animal carcass was done by composting. The farm is in accordance with national and state environmental legislation.
\end{abstract}

Keywords: pig industry; composting; pig carcases of swine waste.

\footnotetext{
1 Eng $^{\mathrm{a}}$ Ambiental, Unicentro, Mestre em Engenharia Sanitária e Ambiental, Unicentro - Uepg, rafaela.eng@meioambiente.eng,br

${ }^{2}$ Bacharel em Ciências Contábeis, Unicentro e Mestrando em Bionergia, Unicentro.

${ }^{3}$ Administrador, Unicentro e Acadêmico de Engenharia Civil, Uniguaçu.

${ }^{4}$ Engo. Industrial - Madeira, Uniuv.
} 


\section{INTRODUÇÃO}

O conjunto de ações empreendidas pela sociedade ou parte dela, com o objetivo de proteger, restaurar, conservar e utilizar de maneira sustentável o meio ambiente pode ser definido como gestão ambiental (PALHARES e MIRANDA, 2007).

O contínuo crescimento do consumo de alimentos gera a necessidade do aumento da produção mundial, visando suprir a demanda. Nesta situação, o Brasil se destaca, pois apresenta condições favoráveis, geográficas e climáticas, no cenário mundial da produção de alimentos. No entanto, esse acréscimo na produção, em diferentes cadeias produtivas, sobretudo nas produções animais, gera consequentemente mais resíduo. Estes resíduos, quando não tratados ou manejados de forma correta causa prejuízos ambientais incontáveis, pois são danosos ao meio ambiente, podendo contaminar lençóis freáticos e cursos d'água (SEBRAE, 2015).

A gestão ambiental em granjas de suínos é de grande importância, visto que compõe um dos elos da cadeia produtiva de animais e merece destaque. Atualmente, o modelo de produção é caracterizado pela criação intensiva e em confinamento, o que concentra grande número de animais em áreas reduzidas, aumentando ainda mais os riscos de contaminação ambiental (KUNZ et al., 2004).

A suinocultura brasileira está bem consolidada, colocando o Brasil como $4^{\circ}$ maior produtor e exportador de carne suína no âmbito mundial. Miele (2007) afirma que cadeia produtiva de carne suína no Brasil apresenta um dos melhores desempenhos econômicos no cenário internacional e a base desse desempenho são as estratégias empresariais e os avanços tecnológicos e organizacionais. A maior parte desse rebanho está concentrada em uma área geográfica relativamente pequena da Região Sul (13 milhões de suínos), aumentando, dessa maneira, o desgaste ambiental e os riscos poluidores desta atividade. No Rio Grande do Sul existem, atualmente, 4.420.325 suínos (OLIVEIRA e NUNES, 2005).

Os principais sistemas de tratamento de dejetos de suínos na forma líquida incluem o uso de compostagem (OLIVEIRA e HIGARASHI, 2006), biodigestores (KUNZ e OLIVEIRA, 2008), esterqueiras, sistemas de decantação e uso de lagoas anaeróbicas e aeróbicas (BELLI FILHO et al., 2001; PRÁ et al., 2005). Além disso, outro problema nas granjas é a destinação das carcaças, cujos métodos tradicionais de disposição de carcaças incluem compostagem, fossas anaeróbias, incineração e enterramento (PAIVA e BLEY JÚNIOR, 2001). 
A lei $n^{\circ}$. 12.305, de 02 de agosto de 2010, que institui a Política Nacional de Resíduos Sólidos, coloca que o crescimento do setor agrosilvopastoril nos últimos anos indica que a geração de resíduos continuará aumentando e, o seu manejo, tratamento e disposição devem ser adequados. Além disso, o Plano Nacional de Resíduos Sólidos, de setembro de 2011, institui como diretriz que, a partir do Censo Agropecuário (2015), todos os resíduos agrosilvopastoris deverão estar inventariados, os resíduos deverão estar quantificados e especializados e os municípios ou regiões com maior volume de resíduos deverão ser identificados.

O objetivo deste trabalho foi caracterizar o perfil de uma granja de suínos da do estado do Paraná e avaliar a forma de destinação das carcaças dos animais mortos bem como verificar se a situação atual está de acordo com a legislação ambiental do Estado do Paraná (INSTITUTO AMBIENTAL DO PARANÁ, 2015).

\section{MATERIAL E MÉTODOS}

Este levantamento foi realizado em granja de criação de suínos, no estado do Paraná. Para coleta dos dados, foram realizadas visitas "in loco" e aplicado um questionário padronizado, a fim de se obter as informações para a realização do estudo.

Os dados coletados foram: identificação da granja, sistema de produção, organização da produção (autônomo ou integrado), número de animais alojados, taxa de mortalidade, destinação da carcaça dos animais mortos e destinação dos dejetos. Para avaliar os dados, foi utilizada uma estatística descritiva.

\section{3 - RESULTADOS E DISCUSSÃO}

A criação de leitões na granja refrente ao estudo é em regime de criação Confinamento e no sistema de UPL (unidade de produção de leitões).

A UPL surgiu devido a necessidade de acelerar os ganhos genéticos, a qualidade da carne e a segurança alimentar está acontecendo uma rápida migração para sistemas especializados. A UPL é destinada a produção e criação de leitões até que atinjam peso e idade adequados. É responsável pela reprodução e criação de leitões em média até os 65 dias e 24,5 kg de peso (MARTINS et al., 2006).

Estes dados diferem de Daga et al. (2007) que verificaram o perfil da suinocultura em 10 propriedades no oeste do Paraná, e concluíram que $80 \%$ dos 
suinocultores operam com produção de terminados (UPT) e $20 \%$ em ciclo completo (CC). Os autores concluíram que essa proporção varia conforme a demanda industrial, a aptidão e o interesse de cada suinocultor, explicação que também pactuamos.

O sistema da granja abriga um plantel atual de 300 matrizes. O número de leitões produzidos é de 550 por mês em um plantel de 300 fêmeas.

No sistema UPL são gerados resíduos sólidos, na maior parte, referente a animais que porventura possam morrer. Abaixo se constam os dados sobre os animais mortos (média) no sistema dividido em categorias bem como o volume dos animais em cada categoria na propriedade:

Tabela 1. Índice de mortalidade da propriedade/categoria

\begin{tabular}{ccc}
\hline Animais adultos/ano & Leitões em creche/ano & Leitões em lactação/ano \\
\hline 15 & 130 & 660 \\
\hline
\end{tabular}

Tabela 2. Volume aproximado/animal segundo cada categoria

\section{Animais adultos Leitões em creche Leitões em lactação}

$0,42 \mathrm{~m}^{3} \quad 0,026 \mathrm{~m}^{3} \quad 0,008 \mathrm{~m}^{3}$

Ressalta-se que logo após a morte, os animais são retirados dos galpões e levados ao respectivo sistema de tratamento.

De acordo com os dados das Tabelas 1 e 2, verificou-se uma ampla variação na taxa de mortalidade e no volume que os animais geram na propriedade. Estes valores mudam de acordo com a fase da criação e com a época do ano, apresentando maiores valores no inverno. De fato, a suinocultura, devido as suas características de produção, apresenta em seu processo produtivo, desde o nascimento até o abate, diferentes etapas que podem submeter os animais à forte estresse, tanto ambiental como de manejo, afetando consideravelmente a produção, levando a perdas por mortalidade (Warriss $e t$ al. 1994).

Área de tratamento e disposição final de resíduos e dejetos devem estar localizadas, de acordo com o Decreto Estadual no 5.503, de 21 de março de 2002, no mínimo, 50 (cinquenta) metros das divisas de terrenos vizinhos, 12 (doze) metros de estradas municipais; 15 (quinze) metros de estradas estaduais; 55 (cinquenta e cinco) metros de estradas federais (INSTITUTO AMBIENTAL DO PARANÁ, 2015). 
O volume $\left(\mathrm{m}^{3}\right)$ é um valor importante para o dimensionamento do sistema a ser implantado na propriedade. Independente do motivo ou da porcentagem, esta pesquisa buscou identificar a destinação destes animais mortos.

\subsection{DESTINAÇÃO DOS RESÍDUOS GERADOS NO PROCESSO DE CRIAÇÃO}

Couto et al., (2010) afirmaram que as formas de descarte de animais mortos incluem aterro, fossas anaeróbias, incineração, alimentação de outras espécies e até mesmo lançamento em córregos e matas, mas os autores relataram que essas maneiras não trazem segurança biológica e ambiental, e também não existe uma reciclagem eficiente dos minerais presentes nas carcaças. Von Zuben Augusto (2010) reportou que, embora o Brasil ainda não conte com uma legislação rigorosa sobre o assunto, o enterro em fossas e a incineração não são práticas recomendadas, porém, são comumente utilizadas.

Buscando uma destinação ambientalmente correta, Von Zuben Augusto (2010) relatou que a compostagem é um dos métodos mais usados e que atende às exigências ambientais de controle de poluição do ar, água e solo. De fato, Couto et al., (2010) referiram que a compostagem de carcaças é uma forma de dispor adequadamente, no ambiente, a mortalidade da criação.

A destinação das carcaças dos animais mortos é para sistema de compostagem. O tratamento adotado justifica-se pelo fato de apresentar maior eficiência de tratamento para os animais mortos e na redução de agentes patogênicos, além de reduzir o mau cheiro e as moscas. Outra vantagem é que o material compostado pode ser utilizado como adubo orgânico na propriedade.

A composteira pode ser construída com madeiras brutas (troncos) ou beneficiada, com menor tempo de vida útil, ou alvenaria de tijolos ou blocos de cimento pré-fabricados. Uma recomendação fundamental está na impermeabilização do solo ou na construção de estrutura acima dele, evitando a contaminação dos lençóis d'água. A adição de água da chuva pode elevar excessivamente a umidade e resultar em uma condição anaeróbia, criando problema de maus odores.

\subsection{PROCESSO DO SISTEMA DE COMPOSTAGEM}


O processo é feito em camadas de cama de aviário (esterco), carcaças de animais, uma palha ou resíduo vegetal e água.

Os materiais devem ser acondicionados, na primeira compostagem, de acordo com a seguinte escala:

1 - Coloca-se $30 \mathrm{~cm}$ de maravalha limpa, cama de aviário ou esterco (seco), no fundo da composteira. Esta camada não fará parte do composto, já que não será umedecido.

2 - Adiciona-se $15 \mathrm{~cm}$ de cama de aviário, palha de milho, feijão, soja, capim seco, folhas secas ou outra fonte de carbono. Essa camada além de fornecer fontes de carbono permite a aeração das carcaças depositadas.

3 - Adiciona-se uma camada de carcaças. Recomenda-se não amontoar pedaços maiores que $30 \mathrm{k}$ de peso. Sendo um animal maior de $30 \mathrm{~kg}$, é necessário fazer cortes em pedaços menores. Faça uma camada de carcaça deixando um espaço de $15 \mathrm{~cm}$ entre uma carcaça e outra, e entre as paredes.

4- Acrescenta-se esterco seco, fazendo um contorno nas carcaças depositadas.

5 - Coloca-se água para umedecer a superfície, na quantidade correspondente a $30 \%$ do peso das carcaças.

6 - Coloca-se esterco seco sobre a parte umedecida, na espessura de $15 \mathrm{~cm}$.

7 - Quando a última camada de carcaça for adicionada a composteira, cobre-se a pilha com uma camada dupla de esterco seco.

O dimensionamento de células de compostagem é feito em função das informações específicas da granja quanto aos seus índices de mortalidades e geração de tecidos mortos (placentas). Com esses índices e com a média dos pesos dos animais em cada uma das fases da produção se tem o volume de carcaças a destinar.

É realizado o monitoramento ambiental do sistema e subsidiam medidas de planejamento, controle, recuperação, preservação e conservação do ambiente de estudo, bem como auxilia na definição das políticas ambientais. $\mathrm{O}$ monitoramento engloba inspeções nas canaletas, e manutenção periódicos das instalações implantadas nos sistemas de tratamento de dejetos (resíduos sólidos), bem como ações de prevenção e correção, para garantir condições operacionais adequadas, objetivando o bom funcionamento do sistema.

\section{4 - CONCLUSÃO}


Os problemas ambientais associados a dejetos de suínos apresentam-se como um grande desafio para a pesquisa, haja vista que os custos das tecnologias desenvolvidas são muitas vezes difíceis de serem transferidos para o setor produtivo por causa da baixa capacidade de investimento do produtor. Isso cria grandes dificuldades para a mitigação dos impactos ambientais da suinocultura, pois, na maioria dos casos, não é possível reduzir a poluição sem agregar tecnologia.

Dentre as possíveis alternativas para solução dos impactos mencionados destacase a utilização do método de compostagem, para as carcaças dos suínos. A compostagem é um método barato e ambientalmente correto que controla a decomposição de matéria orgânica com o objetivo de obter num menor tempo um material rico em nutrientes.

É de fundamental importância dimensionar e planejar os sistemas de tratamento dos resíduos gerados para uma diminuição do impacto ambiental negativo gerado pela atividade.

Conclui-se que o sistema de tratamento adotado na propriedade propicia uma maior eficiência do tratamento das carcaças dos animais mortos, eficiência na redução de possíveis agentes patogênicos, redução de mau cheiro e de moscas no local e ao redor e a possibilidade de uso do material compostado para adubação orgânica na propriedade.

A granja estuda está em concordância com o capítulo 3 do Plano Nacional de Resíduos Sólidos, de setembro de 2011, que elenca como destinação adequada para os resíduos da criação animal a compostagem e/ou biodigestores ou outras tecnologias. Contudo, o Plano salienta que as estratégias de utilização devem envolver a avaliação do potencial dos resíduos da criação animal como fonte de nutrientes e condicionadores de solo ou para a geração de energia, além de estimular o desenvolvimento de tecnologias de aproveitamento de resíduos da criação animal visando à redução da contaminação biológica.

\section{REFERÊNCIAS}

BELli FILHO, P., CASTIlHOS Jr, A. B., COSTA, R. H. R., SOARES, S. R., PERDOMO, C. C. Tecnologias para o tratamento de dejetos de suínos. R. Bras. Engenharia Agrícola e Ambiental, Campina Grande, v.5, n.1, p.166-170, 2001.

BRASIL. Plano Nacional de Resíduos Sólidos. Versão Preliminar para Consulta Pública Brasília, DF, set. 2011. Disponível em: 
<http://www.mma.gov.br/estruturas/253/_publicacao/253_publicacao02022012041757. pdf>, acessado em 22/06/2015.

BRASIL. Política Nacional de Resíduos Sólidos, Lei 12.305. Institui a Política Nacional de Resíduos Sólidos; altera a Lei no 9.605, de 12 de fevereiro de 1998; e dá outras providências. Diário Oficial da República Federativa do Brasil, Brasília, DF, 2 ago. 2010. Disponível em:< http://www.planalto.gov.br/ccivil_03/_Ato20072010/2010/Lei/L12305.htm> Acesso em: 22 jun. 2015.

COUTO, G.E.; SILVA, D.B.; SILVA, C.H.P.; PAES, M.J.P.; FRANÇA NETO, O. Desempenho de compostos de carcaça de aves. In: IBEAS - Congresso Brasileiro de Estudos Ambientais. I. 2010. Bauru. Anais... Bauru: IBEAS, 2010.

DAGA, J.; CAMPOS, A.T.; FEIDEN, A.; KLOSOWSKI, E.S.; CÂMARA, R.J. Análise da adequação ambiental e manejo dos dejetos de instalações para suinocultura em propriedades na região Oeste do Paraná. Engenharia Agrícola, Jaboticabal, v.27, n.3, p.587-595, 2007.

INSTITUTO AMBIENTAL DO PARANÁ. Cartilha para Suinocultura. Disponível em: $<$ http://www.iap.pr.gov.br/arquivos/File/Atividades/cartilha_suino.pdf $>$. Acesso em: 20/12/2015.

KUNZ, A.; SCHIERHOLT NETO, G. F.; NUNES, L. M. A.; OLIVEIRA, P.A. Estudo da relação maravalha/dejeto a diferentes umidades para incorporação de lodo de dejeto de suínos, Florianópolis, 2004. p.2193 - 2198. In: Anais..., Congresso Brasileiro de Ciência e Tecnologia em Resíduos e Desenvolvimento Sustentável, 2004, Florianópolis. $2004 . \quad$ Disponível em < https://www.ipen.br/biblioteca/cd/ictr/2004/ARQUIVOS\%20PDF/01/01-003.pdf>

MARTINS, F M; TALAMINI, T J D; ARBOIT, C; WOLOZSYN, N. Análise econômica da produção integrada de suínos nas fases de leitões e de terminação. Custos e @ gronegócio on line - v.2 - Edição Especial - Out - 2006. p. 18 - 34. Disponível: < http://www.custoseagronegocioonline.com.br/especialv2/analise $\% 20 \mathrm{de} \% 20$ producao $\%$ 20integrada.pdf>

MIELE, M. ; WAQUIL, P. D. Cadeia produtiva da carne suína no Brasil. Revista de Política Agrícola, v. 16, p. 75-87, 2007.

OLIVEIRA, P. A. V., HIGARASHI, M. M. Unidade de compostagem para o tratamento dos dejetos de suínos. Documentos 114. Concórdia. Embrapa Suínos e Aves 2006. Disponível em http://www.google.com.br/url?url=http://www.cnpsa.embrapa.br/down.php\%3Ftipo\%3 Dpublicac oes\%26cod_publicacao\%3D918\&rct=j\&frm =1\&q=\&esrc=s\&sa=U\&ei=7vo3VZbrO8L QtQWMzYHYA w\&ved=0CBQQFjAA\&sig2=cxjjj82gco0erEf506fi6A\&usg=AFQjCNE9Piotr3jnZSIRv f4tzdkXaQ6HQ w, acessado em 17/04/2015.

OLIVEIRA, P. A. V., NUNES, M. L. A. Sustentabilidade ambiental da suinocultura. Workshop sobre Tecnologias para a Remoção de Nutrientes de Dejetos de Origem Animal. Embrapa Suínos e AvesSanta Catarina. 2005. Disponível em http://www.cnpsa.embrapa.br/sgc/sgc_publicacoes/anais0205_oliveira.pdf, acessado em 20/04/2015. 
PAIVA, D.P.; BLEY JÚNIOR, C. Emprego da Compostagem para Destinação Final de Suínos Mortos e Restos de Parição. Circular Técnica, 26. Embrapa Suínos e AvesSanta Catarina, 2001.

PALHARES, J. C. P.; MIRANDA, C. R. Gestão Ambiental da propriedade suinícola. In: SEGANFREDO, M. A. (Ed.). Gestão Ambiental na Suinocultura. Brasília, DF:Embrapa Informação Tecnológica, 2007. Cap. 12, p. 287-302.

PRÁ, M. A. D. ; KONZEN, E. A.; OLIVEIRA, P. A.; MORES, E. Compostagem de Dejetos Líquidos de Suínos. Documentos 45. Embrapa Milho e Sorgo - Sete Lagoas, 2005.

SEBRAE - PORTAL DA AGROENERGIA. Disponível em http://201.2.114.147/bds/BDS.nsf/5B18771A2EE876568325753D005A20DF/\$File/NT 0003DAF2.pdf acessado em 20/04/2015.

VON ZUBEN AUGUSTO, K. Vida após a morte: compostagem de carcaças. Revista Avicultura Industrial, ago/ 2010. Disponível em http://www.aviculturaindustrial.com.br/noticia/vida-apos-amorte-compostagem-decarcacas-por-karolina-von-zuben-augusto/20101008131556_B_228, acessado em $18 / 04 / 2015$.

WARRISS, P.D.; BROWN, S.N.; ADAMS, S.J.M. Relationships between subjective and objective assessments of stress at slaughter and meat quality in pigs. Meat Science, Kidlington, v.38, p.329- 340, 1994 